\title{
Trepp, Ann-Charlott, Von der Glückseligkeit, alles zu wissen. Die Erforschung der Natur als religiöse Praxis in der Frühen Neuzeit
}

\section{Axelle Chassagnette}

\section{OpenEdition}

\section{Journals}

Édition électronique

URL : http://journals.openedition.org/ifha/6523

DOI : $10.4000 /$ ifha.6523

ISSN : 2198-8943

Éditeur

IFRA - Institut franco-allemand (sciences historiques et sociales)

Référence électronique

Axelle Chassagnette, «Trepp, Ann-Charlott, Von der Glückseligkeit, alles zu wissen. Die Erforschung der Natur als religiöse Praxis in der Frühen Neuzeit », Revue de I'IFHA [En ligne], Date de recension, mis en ligne le 01 janvier 2012, consulté le 22 septembre 2020. URL : http://journals.openedition.org/ifha/ 6523 ; DOI : https://doi.org/10.4000/ifha.6523

Ce document a été généré automatiquement le 22 septembre 2020.

(CIFHA 


\title{
Trepp, Ann-Charlott, Von der Glückseligkeit, alles zu wissen. Die Erforschung der Natur als religiöse Praxis in der Frühen Neuzeit
}

\author{
Axelle Chassagnette
}

1 La belle étude d'A.-C. T., issue d'une thèse d'habilitation, part de l'idée, aujourd'hui largement acceptée, que sciences et religion furent étroitement imbriquées à l'époque moderne et qu'elles purent entretenir des relations fructueuses et non conflictuelles. L'ouvrage porte sur la période des XVIIe et XVIIIe siècles et sur l'espace germanique. Trois études monographiques en constituent le cœur, consacrées aux théologiens Johann Rist (1607-1667) et Friedrich Christian Lesser (1692-1754) ainsi qu'à la figure de Maria Sibylla Merian (1647-1717), naturaliste, dessinatrice et peintre. Il s'agit dans les trois cas de personnalités protestantes, proches des formes de piété alternatives - en particulier du piétisme - qui se développent dans le luthéranisme de l'Empire à partir des premières décennies du XVIIe siècle. Pour A.-C.T., l'orientation vers l'étude passionnée et pieuse de la nature que l'historien découvre dans ces milieux peut s'expliquer de différentes manières. Un des facteurs fut sans doute la lassitude ressentie devant les constantes discussions théologiques menées dans les milieux luthériens, dans le but d'établir une doctrine orthodoxe toujours fuyante. Une autre explication peut être trouvée dans le besoin, qui se fit plus urgent en temps de crises, de trouver un chemin individuel et spontané, en partie détaché de l'étude biblique, vers la recherche du salut. De manière plus prosaïque, l'auteure relève enfin que les pasteurs, souvent isolés des milieux savants, purent trouver une compensation à leur relative solitude intellectuelle dans les travaux naturalistes et dans la pratique de la collection.

2 Le premier chapitre est consacré à une contextualisation du développement des études de la nature dans l'espace germanique au XVIIe siècle, en particulier dans sa première moitié, marquée notamment par la guerre de Trente Ans et le petit âge glaciaire. 
L'auteure y décrit le développement, dans les milieux luthériens, de pratiques dévotionnelles plus individuelles et plus spontanées. Elle insiste en particulier sur la très grande influence exercée par le pasteur Johann Arndt (1555-1621) et par son ouvrage, Vier Büchern vom wahren Christentum, publié pour la première fois à Magdebourg en 1610, réédité et traduit de nombreuses fois. Arndt promeut la pratique d'une piété individuelle intense, fondée sur l'association étroite entre croyance et existence quotidienne et sur la recherche d'une véritable expiation. Il souligne l'importance de l'étude et de l'observation de la nature, conçue comme un tout organique et habité par Dieu. La naissance de l'ordre hermétique des Rose-Croix dans un contexte d'attente apocalyptique est aussi assez longuement étudiée. Ce mouvement philosophique et religieux a cherché à découvrir les secrets de la nature, en particulier par l'approche alchimique. Le second chapitre porte sur Johann Rist. Pasteur luthérien, naturaliste, médecin, collectionneur et alchimiste, copernicien convaincu et adepte des théories de Paracelse, il est surtout connu pour son œuvre poétique abondante. Son œuvre ne comprend pas d'écrits théoriques qui révéleraient la mise en œuvre d'une philosophie naturelle élaborée. En revanche, elle témoigne d'une observation continue et enthousiaste de la nature, vécue comme une urgence devant l'imminence de la fin des temps. Cette attente eschatologique, très répandue dans les milieux luthériens depuis le XVIe siècle et accentuée dans les décennies difficiles du XVIIe siècle, conduit Rist à considérer son époque comme un sommet du développement des arts et des sciences, que l'homme doit sans relâche chercher à perfectionner. Le chapitre suivant s'attache à l'étude d'une autre figure célèbre, celle de Maria Sibylla Merian. Fille du graveur et éditeur francfortois Matthäus Merian, Maria Sibylla, à défaut de recevoir une éducation scolaire, effectue un véritable apprentissage des techniques de dessin, de gravure et de peinture. Son goût la porte dès l'enfance vers l'observation de la nature, de la flore et des insectes, en particulier des papillons : le ver à soie constitue l'un de ses premiers sujets d'observation. Ces travaux font l'objet de publications qui vont conférer à Maria Sibylla Merian une renommée européenne : il s'agit d'ouvrages en allemand, d'une grande qualité esthétique, mais également d'un très grand intérêt scientifique et qui mettent clairement en lumière la métamorphose des insectes. De confession luthérienne, Merian se sépare de son époux pour vivre quelques années avec ses deux filles dans une communauté piétiste de Frise occidentale, dans le château de Waltha, tout en entretenant des échanges intellectuels suivis avec un certain nombre de savants et collectionneurs d'Amsterdam. Un voyage et un séjour au Surinam lui permettent de publier un ouvrage sur la faune et la flore de la région. La plupart de ses travaux révèlent, chez elle, une corrélation étroite entre observation de la nature et reconnaissance de l'œuvre et de l'action divines dans le monde. Le quatrième chapitre permet à nouveau à l'auteure, ici pour la période allant du XVIIe siècle au milieu du XVIIIe siècle, de rappeler le développement des mouvements incitant à l'étude de la nature comme chemin de connaissance et de reconnaissance de Dieu. Est évoqué le mouvement " physico-théologique " allemand (que l'on nomme plutôt " théologie naturelle » en français) né au XVIIe siècle, qui cherche à établir la preuve de l'existence, la reconnaissance de Dieu et de ses desseins, dans l'observation de la Création, et donc en particulier dans l'étude de la nature. A.-C. T. traite par ailleurs des nouveaux développements du piétisme au XVIIIe siècle, en particulier à Halle autour de August Hermann Francke. Le dernier et sixième chapitre a pour principal sujet le pasteur Friedrich Christian Lesser, naturaliste et collectionneur (en particulier d'insectes, de minéraux et de coquillages), correspondant de nombreux savants européens. Son 
admiration pour l'œuvre de Dieu et son étude de la nature le portent en particulier vers le petit et l'infiniment petit, où, affirme-t-il, se lit à merveille la perfection de la Création. Homme de son temps, il associe à la compréhension spécifiquement luthérienne de la Providence, qui conçoit que Dieu est toujours présent et actif dans le monde, une conception mécaniste des phénomènes naturels, qui conforte la description savante des lois et des règles naturelles.

3 A.-C. T. parvient donc parfaitement à combiner l'approche monographique et la perception du temps long. L'étude méticuleuse des travaux et de la pensée de ses trois principaux personnages est en effet toujours l'occasion de revenir de manière approfondie sur la production et la réception d'un certain nombre de doctrines savantes et théologiques, sur l'éducation et les échanges qui ont nourri l'activité et la réflexion de Rist, Merian et Lesser. L'auteure met ainsi en lumière, sur près d'un siècle et demi, la continuité d'un enthousiasme religieux pour l'étude et l'émerveillement devant la nature dans les milieux luthériens, tout en soulignant la variété et l'évolution des contextes philosophiques (de l'hermétisme au mécanisme en passant par la philosophie de Paracelse) et confessionnels (en particulier piétistes) qui innervent la pensée et les travaux des protagonistes de cet ouvrage.

4 Axelle Chassagnette (Université Lyon II) 